\title{
Gênero e História das Mulheres: reflexões sobre a experiência de estágio na Educação de Jovens e Adultos
}

\author{
Andréia Amorim da Silva* \\ Rodrigo Porto ${ }^{* *}$
}

\begin{abstract}
Resumo
O presente texto tem por objetivo discorrer acerca da valiosa experiência de estágio supervisionado de História, desenvolvido na Educação de Jovens e Adultos (EJA), em Florianópolis (SC), sob orientação da professora Claricia Otto. Além das atividades integrantes do Estágio junto ao Núcleo da EJA em que atuamos - EJA NORTE I - Escola Básica Municipal Herondina Medeiros Zeferino, elaboramos e desenvolvemos uma oficina em torno da temática, Gênero e História das Mulheres. Neste texto, procuramos apresentar, de forma analítica, como o assunto vem sendo tratado nos meios de comunicação, assim como objetivamos demonstrar todo o processo de elaboração da oficina e dos desafios e aprendizados desta experiência.
\end{abstract}

Palavras-chave: estágio supervisionado de história, educação de jovens e adultos, gênero.

Gender and women's history: reflections about the internship experience of youth and adult education

\begin{abstract}
This article aims to discuss the valuable experience in the Supervised Internship in History Teaching of Youth and Adult Education (Educação de Jovens e Adultos - EJA) at Florianópolis (Santa Catarina), under the guidance of Professor Claricia Otto. Besides the activities of the Internship at the EJA Nucleus where we work - EJA NORTE 1 -EscolaBásica Municipal Herondina Medeiros Zeferino, we developed a workshop about Gender and Women's History.In this text, we attemptto present analytically how the subject has been treated in the mediaas well as we aim to demonstrate the entire workshop process and the challenges and learning from this experience.
\end{abstract}

Keywords: supervised internship in history, youth and adult education. gender.

\section{Introdução}

Este texto é resultado de reflexões e de muitas orientações até que chegasse ao formato atual a fim de ser compartilhado com um público maior. Aqui abordamos alguns elementos de nossa experiência de estágio em um núcleo de Educação de Jovens e Adultos (EJA) em Florianópolis, no ano de 2015. Essa atividade de estágio é integrante do currículo do Curso de Licenciatura em História na Universidade Federal de Santa Catarina (UFSC).

A experiência teve início com a observação do campo de estágio durante o primeiro semestre de 2015. Assim, diante das reflexões do andamento das atividades do Núcleo EJA NORTE I, Escola Básica Municipal Herondina Medeiros Zeferino, no

* Graduada em História pela Universidade Federal de Santa Catarina. E-mail: andreia.amorim@gmail.com.

** Graduado em História pela Universidade Federal de Santa Catarina. E-mail: rodriguporto@gmail.com. 
bairro dos Ingleses, conversas em dupla e com a professora responsável pela disciplina, optamos por ministrar uma oficina intitulada "Igualdade de Gênero e História das Mulheres". Portanto, neste texto, serão debatidos os caminhos que nos levaram à escolha de trabalhar com questões de gênero e história das mulheres, como foi relevante essa perspectiva a fim de compreender a vivência no Núcleo e também a importância de se trabalhar com esta temática para oportunizar um debate sobre um assunto que tem suscitado diversas discussões junto à sociedade. O conceito de gênero neste trabalho é debatido com base nas proposições de Joan Scott (1989, p. 21):

Minha definição de gênero tem duas partes e várias sub-partes. Elas são ligadas entre si, mas deveriam ser analiticamente distintas. O núcleo essencial da definição baseia-se na conexão integral entre duas proposições: o gênero é um elemento constitutivo de relações sociais baseado nas diferenças percebidas entre os sexos, e o gênero é uma forma primária de significar as relações de poder.

O conceito é importante para entender que os sujeitos da EJA estão inseridos em uma sociedade que ainda trata de maneira diferente homens e mulheres e de quanto isso também contribui, de alguma maneira, na construção de suas respectivas subjetividades. A perspectiva dos estudos de gênero, portanto, evidencia que as diferenças no modo como homens e mulheres são tratados ou compreendidos em sociedade são construídas socialmente através do tempo. A compreensão desse conceito busca desnaturalizar e desconstruir diferenças que são construídas socialmente.

A EJA é voltada para estudantes a partir de 15 anos completos que não finalizaram o ensino fundamental em seu período regular por diversos motivos. Os alunos e alunas habitam o mesmo bairro da escola, ou seja, dos Ingleses, ou localidades próximas. A escola contém uma boa estrutura para as suas atividades, existem salas bem equipadas, uma biblioteca, um refeitório onde acontecem os jantares e uma sala de informática que é utilizada pelos estudantes sob orientação dos professores. A metodologia de ensino adotada pela EJA em Florianópolis é o de educar pela pesquisa, definido de Pesquisa como Princípio Educativo (PPE). A pesquisa é construída pelos estudantes em grupos que devem trabalhar em diversas etapas para a realização da mesma. Os passos para a elaboração são: definição de uma problemática, justificativa, hipótese, saberes prévios, mapa da pesquisa, plano de trabalho, apresentações parciais e finais. 
O grupo de estudantes que participava das aulas era heterogêneo. Havia tanto homens quanto mulheres, pessoas mais velhas e mais novas. Uma surpresa foi a expressiva quantidade de jovens. Usar as ideias de gênero para compreender este grupo possibilita algumas reflexões. Por exemplo, foi possível visualizar momentos, durante a observação no Núcleo, onde meninas recebiam "assobios" quando passavam perto de meninos que buscavam chamar sua atenção. Por um lado, é possível compreender esta prática como uma certa "naturalização" da sexualidade pela qual as mulheres passam a ser vistas como "objetos" a serem admirados e que necessitam de algum elogio nesse sentido. Certamente, nem no Núcleo de estudo ou em outros espaços, os homens são tratados dessa mesma forma. Dessa maneira, uma das inquietações iniciais sobre como seria organizada a oficina surgiu ao constatarmos como as diferenças no tratamento entre homens e mulheres permeiam, inclusive, o ambiente escolar. Centramos, inicialmente, nossas reflexões nas mulheres que vivenciavam o Núcleo.

Apesar das dificuldades em se apontar diretamente os motivos que levaram mulheres a pararem seus estudos e precisarem freqüentar a EJA, sabe-se que diversas práticas são costumeiramente impostas às mulheres na sociedade que dificultam a realização de sua formação no tempo previsto. Pode-se apontar exemplos como: a maternidade que, ainda hoje, tende a ser quase uma obrigação exclusiva da mulher, a necessidade de cuidados de familiares ou trabalhos domésticos e também a violência doméstica que pode levar algumas mulheres a serem impedidas, por força ou medo, de sair de casa para estudar ${ }^{1}$. Assim, é importante sublinhar que a conquista de maiores direitos e um tratamento igual para as mulheres possui uma longa história marcada por avanços, recuos e muitos setores que buscam barrar novas conquistas.

É alarmante saber que há, por parte de determinados grupos da sociedade, tentativas de chamar, de modo pejorativo, discussões de gênero como "Ideologia de Gênero" ou também a proibição de que ocorram estas discussões em sala de aula. Abordaremos um pouco sobre este debate que contribuiu para a escolha da temática de

Segundo pesquisa do Instituto Unibanco com base nos últimos dados do IBGE sobre a evasão escolar, pode-se dizer que dentre as pessoas com maior risco para não seguir os estudos estão "jovens de baixa renda, em sua maioria negros, que trocam com frequência os estudos por um trabalho precário ou que ficam grávidas já na adolescência". Além disso, o estudo aponta que somente $2 \%$ das adolescentes que engravidaram deram sequências aos estudos. Estudo mostra que 1,3 milhão de jovens de 15 a 17 anos abandonam a escola. Agência Brasil. 27/02/2016. Disponível em: < http://agenciabrasil.ebc.com.br/educacao/noticia/2016-02/13-milhao-de-jovens-entre-15-e-17-anosabandonam-escola-diz-estudo>. Acesso em 15 fev. 2017. 
gênero e história das mulheres para a oficina. São questões que continuam gerando tomadas de posição que nem sempre primam pela luta por igualdade entre homens e mulheres, portanto, quando se abordar algum material posterior ao ano de 2015 será para demarcar como o assunto não se esgotou na realização de debates.

Em uma nota do Ministério da Educação (MEC) intitulada "MEC Repudia tentativas de cerceamento dos princípios e fins da educação brasileira" de 4 de maio de 2016 está exposto:

\begin{abstract}
Vimos a público manifestar nossa indignação frente a recentes iniciativas de setores da sociedade que buscam cercear os princípios e fins da educação nacional, mais especificamente acerca de documentos autodenominados "notificações extrajudiciais contra o ensino de 'ideologia de gênero' nas escolas (MERCADANTE, 2016).
\end{abstract}

Essa nota é significativa também ao discorrer acerca da importância de a escola abordar temáticas como o preconceito, a violência física, psicológica ou moral; o preconceito religioso, de gênero, orientação sexual, raça, ou seja, quaisquer formas de discriminação. O professor que aborda o preconceito e trabalha com o desenvolvimento de uma cultura de paz, respeito e tolerância em sala de aula, "cumpre os objetivos fundamentais da Constituição Federal, que pretende garantir um Brasil sem discriminação" (MERCADANTE, 2016).

Um texto intitulado “A 'ideologia de gênero' e as ameaças à democracia”, de meados de 2015 e autoria de Flávia Birolli, evidencia como a democracia e os direitos individuais estão ameaçados por ofensivas contra o que vem sendo chamado de 'ideologia de gênero'. Segundo a autora, “trata-se da ação retrógrada, orquestrada, de alguns grupos religiosos na política" (BIROLI, 2015). Birolli expõe como movimentos sociais, que possuem as questões de gênero como parte da sua agenda, denunciam que certos grupos possuem menos chances de ser respeitados e são alvos de violências e humilhações cotidianas. No ambiente escolar, formas de discriminação e desvalorização produzem sofrimentos e reduzem o aproveitamento de muitas crianças:

O que está em questão é se teremos diretrizes educacionais orientadas para a igualdade, a tolerância e a diversidade ou fundadas em noções de superioridade, em visões exclusivas e excludentes. De maneira mais ampla, o que está em questão nesse momento é a nossa democracia e a capacidade que teremos, como sociedade, de garantir o respeito aos direitos individuais (BIROLLI, 2015). 
A partir da aprovação do Plano Nacional de Educação (PNE - Lei no 13.005, de 25 de junho de 2014), que traz como uma de suas diretrizes a "superação das desigualdades educacionais, com ênfase na promoção da cidadania e na erradicação de todas as formas de discriminação" (BRASIL, 2014), foi iniciada a construção de Planos Estaduais e Municipais, o que trouxe à tona um maior debate em torno da dimensão do gênero e orientação sexual nos planos de educação, conforme foi expresso em nota técnica de Secretarias e outros órgãos do MEC (CASTRO, et al., 2015). A nota discorre sobre a temática e como o gênero permeia o ambiente escolar, isto é, a sociedade.

O conhecimento científico já produzido neste campo nos leva à compreensão de que o centro do debate não está em se a escola deve ou não falar sobre gênero e orientação sexual, mas sim em perceber como ela já fala - onde, quando, por que caminhos e com que efeitos (CASTRO, et. al; 2015).

Uma vez que gênero estava na ordem do dia nas discussões educacionais, a escolha de abordar esta temática foi se consolidando. Além disso, diante de manifestações autoritárias e preconceituosas sobre o assunto, pode-se perceber com maior evidência certa faceta conservadora da sociedade.

Convém notar que nestes últimos anos o autoritarismo e pensamentos conservadores ganharam mais espaço e força para se manifestarem, inclusive em espaços políticos representativos. No livro "Como conversar com um fascista" a filósofa Márcia Tiburi (2015, p. 30) expõe sobre o cotidiano de autoritarismo brasileiro:

Podemos assim dizer que o ódio transita entre nós. Mas o curioso é que isso
não acontece somente de maneira inconsciente. Há algo assustador no ódio
contemporâneo. Não se tem vergonha dele, está autorizado hoje em dia e não
é evitado. A estranha autorização para o ódio vem de uma manipulação não
percebida a partir de discursos e de dispositivos criadores desse afeto. Somos
seres capazes de amar e odiar. O motivo pelo qual amamos é inversamente
proporcional ao porque odiamos. No primeiro caso construímos, no segundo,
destruímos.

$\mathrm{Na}$ direção dessa perspectiva, no prefácio do livro, o deputado federal Jean Willys destaca como o direito a uma educação de qualidade e cidadã há décadas não esteve presente para a maioria da população brasileira. A ampliação do acesso à educação não significou que esta fosse de qualidade, voltada ao pensamento crítico e de reconhecimento da diversidade cultural e humana. Ele insiste sobre a necessidade de se lutar para que ocorra o acesso à educação de qualidade e que ocorra um maior diálogo 
mesmo com os que a autora considera fascistas. O autor também assevera o papel dos meios de comunicação neste debate. Uma vez que a maioria da população se informa apenas por tevês e rádios - onde não há um grande aprofundamento das questões de interesse público e informações estão de acordo com interesses políticos e financeiros de seus concessionários ou administradores - isto tendeu a contribuir para que parte expressiva da população esteja aderindo

[...] aos discursos demagógicos e manipuladores que interpelam preconceitos e sensos comuns históricos e propõem soluções fáceis, mas mentirosas e/ou autoritárias para as questões complexas que nos envolvem diariamente, como a criminalidade e a violência urbanas, as desigualdades social e de gênero (...). Essa situação, acrescida da lógica egoísta - 'farinha pouca, meu pirão primeiro' - que as crises econômicas e/ou financeiras como a que estamos vivendo costumam trazer são provas irrefutáveis do retorno e reencarnação de um fantasma perigoso chamado fascismo (WILLYS, 2015, p.18).

Uma iniciativa na UFSC, diante desses acontecimentos, foi a construção de uma cartilha intitulada "Você já ouviu falar sobre igualdade de gênero?" na qual, de uma maneira simples e direta, é explicado o que é a igualdade de gênero e a importância de se debater este assunto nas escolas. Está escrito sobre como o debate de gênero trabalha a favor de uma escola mais inclusiva e com menos preconceitos, pois as escolas devem ser espaços transformadores onde futuras gerações aprendam a respeitar diferenças de gênero, de etnia, orientação sexual, classes etc. Portanto, "Promover a igualdade de gênero não significa anular as diferenças, mas garantir que a escola seja um espaço democrático onde essas diferenças não se transformem em desigualdades" (CARTILHA SOBRE IGUALDADE DE GÊNERO, 2015).

Embora, conforme foi apresentado, existam diversos grupos e autores que tratam das discussões de gênero em defesa de uma educação inclusiva e cidadã, há setores tradicionais da sociedade que tratam as discussões de gênero pejorativamente chamando-as de "ideologia de gênero". Na internet é fácil encontrar diversos sites que apresentam discursos desse teor, normalmente são endereços eletrônicos de grupos políticos, grupos de direita, alguns se auto intitulam conservadores e também religiosos. Dentre alguns dos argumentos utilizados contra a inserção do gênero em documentos educacionais estão: que isto acarretaria em um gasto desenfreado de dinheiro público para modificar o comportamento sexual das crianças; que a ideologia de gênero pretende manipular a personalidade dos filhos e filhas; que as crianças não saberão se 
são meninos ou meninas; que essas discussões são ataques contra a família e que estimulam a promiscuidade. Além disso, estes textos utilizam estratégias para chamar a atenção de suas ideias, tais como a referência a estudos estrangeiros ou uso de frases de impacto que sinalizam que existe hoje em dia um ataque contra a "família", os "bons costumes" e a "moral". 2

Inicialmente, parece não existir um diálogo entre estes dois grupos - os que defendem a discussão de gênero e os que são contra - sendo que, até onde foi possível visualizar, a maior parte daqueles que se posicionaram a favor das discussões de gênero encontram-se próximos de universidades ou estão em contato de alguma maneira com esses estudos. Assim, o que se entende por gênero, isto é, o conceito que é amplamente debatido em ambientes acadêmicos que pesquisam a história das mulheres, feminismo etc., tal como o que é proposto por Joan Scott, e que pode ser considerado como uma teoria básica para este assunto, não encontra-se presente ou é mencionado nos espaços opositores. Desse modo, "ideologia de gênero", para os que lhe são contrários, parece muito mais um conjunto de "doutrinas" que buscam "corromper" uma suposta "normalidade" da sociedade e destruir um padrão de família formado por um homem, uma mulher e seus filhos.

Com relação ao que se entende por ideologia, não parece claro e não é discutido o seu significado nos materiais consultados. Ideologia parece se confundir com uma "doutrinação" capaz de enganar aos que lhe são destinatários. Sobre este conceito, existem diversos estudos sobre o que significa. Na obra "O que é ideologia" de Marilena Chauí, por exemplo, ideologia é considerada como um instrumento de dominação de classe. A autora é tributária das discussões de Karl Marx sobre este termo e, a partir da obra desse autor, discorre que,

[...] o papel específico, da ideologia como instrumento da luta de classes é impedir que a dominação e a exploração sejam percebidos em sua realidade concreta. Portanto, é função da ideologia dissimular e ocultar a existência das divisões sociais como divisões de classe, escondendo, assim, sua própria origem. Ou seja, a ideologia esconde que nasceu da luta de classes para servir a uma classe de dominação (CHAUí, 1981, p.103).

\footnotetext{
Alguns dos sites consultados são: Você já ouviu falar sobre a "ideologia de gênero"?.Observatório interamericano de biopolítica. Disponível em: <http://biopolitica.com.br/index.php/cursos/40-voce-ja-ouviu-falar-sobre-a-ideologia-degenero>. Acesso em 29 de maio de 2016; O que é Ideologia de Gênero. Catedral Metropolitana. N.S. Auxiliadora Goiás. Disponível em: 〈http://www.catedralgo.com.br/index.php/midias/noticias/244-o-que-e-ideologia-de-genero>. Acesso em: 29 de maio de 2016; Associação Americana de Pediatras fulmina ideologia de gênero. ChristoNihilPraeponere. 06/05/2016. Disponível em: 〈https://padrepauloricardo.org/blog/tag/443-ideologia-de-genero〉. Acesso em: 29 mai. 2016.
} 
É possível afirmar que a noção "ideologia", para os que dizem que existe uma “ideologia de gênero", é diferente do que Chauí expôs. Assim, o modo como essa autora defende que deva ser a atividade intelectual frente ao que se entende por uma ideologia é de que se deve lutar para superar as diferenças e desigualdades que atravessam as relações sociais. Por outro lado, para quem defende que existe uma "ideologia de gênero", parece haver em seu projeto de luta a proposição de se conservar diferenças e desigualdades entre gêneros.

Assim, ao que foi possível analisar, os que criticam os estudos de gênero não parecem buscar dialogar ou até mesmo criticar o que tem sido debatido em ambientes de pesquisa sobre esse tema. Existem riscos em considerar essas "duas posições" como de igual valor ou profundidade, pois, os estudos de gênero estão vinculados a lutas sociais que permeiam a sociedade há algumas décadas e são fruto de investigações e análises cujo rigor é o do meio acadêmico onde este tema está também inserido. Deve-se ressaltar isso, pois existem momentos e espaços jornalísticos, por exemplo, que tratam estas "duas perspectivas" como de mesma relevância sendo indiferente qual a formação dos que as propõem.

A escolha da temática da oficina, portanto, pode ser compreendida melhor a partir desse contexto de debates e discussões a respeito de gênero. É sabido que, apesar desse assunto ter estado em jornais, revistas ou outros meios de comunicação, isto não significa, necessariamente, que os alunos e as alunas tenham tido contato com ele, e que o assunto tenha recebido uma reflexão adequada ou mesmo aprofundada. Além disso, conforme já foi exposto, é raro encontrar nos maiores meios de comunicação espaços para debates reflexivos. Normalmente, os atuais programas encerram os debates na contraposição de duas supostas perspectivas com igual valor, ou seja, parece haver certo predomínio, sobretudo na internet, em se apresentar notícias mais concisas que, certamente, não se aproximam da complexidade dos fatos.

História das mulheres e gênero em sala de aula: elaboração e desenvolvimento de uma oficina

A partir daqui discutiremos como foi o processo de criação da oficina e o que observamos que possa ter sido a construção de conhecimento por parte dos alunos da EJA. Uma inquietação que permeou a escolha temática foi de termos ouvido relatos 
sobre alunos e alunas cujos problemas familiares estavam próximos do que se entende por violência de gênero, isto é, violências físicas e psicológicas sofridas pelas mulheres por seus companheiros ou familiares. Isso teve de ser levado em conta na elaboração da oficina para não abordarmos algo relacionado com essas questões como distante e fora da realidade cotidiana. A oficina teve cerca de 2 horas de duração (sem intervalo). Utilizamos, como material principal, slides em formato Power-point, com imagens e vídeos que foram dialogados e problematizados.

Iniciamos a oficina tomando como ponto de partida uma problematização sobre o que é igualdade de gênero, e como os papéis de homens e mulheres, meninos e meninas são construídos na sociedade e reforçados por meio de propagandas, por exemplo. Depois de apresentado o tema e o que são esses conceitos de gênero, papeis de gênero ou igualdade de gênero, tentamos historicizar como esses papeis foram construídos de maneiras diferentes ao longo do tempo. Demos ênfase ao que era considerado como o "papel da mulher" e como esta era vista em diferentes períodos, tais como: a mulher na Grécia e Roma antiga; a mulher na Idade Média e Moderna; a mulher no século XX (1901-2000). Essas questões foram expostas de maneira sucinta para desnaturalizar uma ideia de que o que se "espera" de uma mulher ou homem na sociedade hoje em dia nem sempre foi o mesmo, está em constante mudança, mas também apresenta certas permanências.

Por exemplo, foram trabalhadas imagens em jornais e revistas do século XX direcionadas às mulheres que reforçavam um estereótipo de gênero de mulher tendo como atribuição o trabalho doméstico e do lar, e como isso também era construído desde a infância. Por exemplo, a Figura 1 mostra um desses slides. 
Figura 1 - A mulher no século XX.
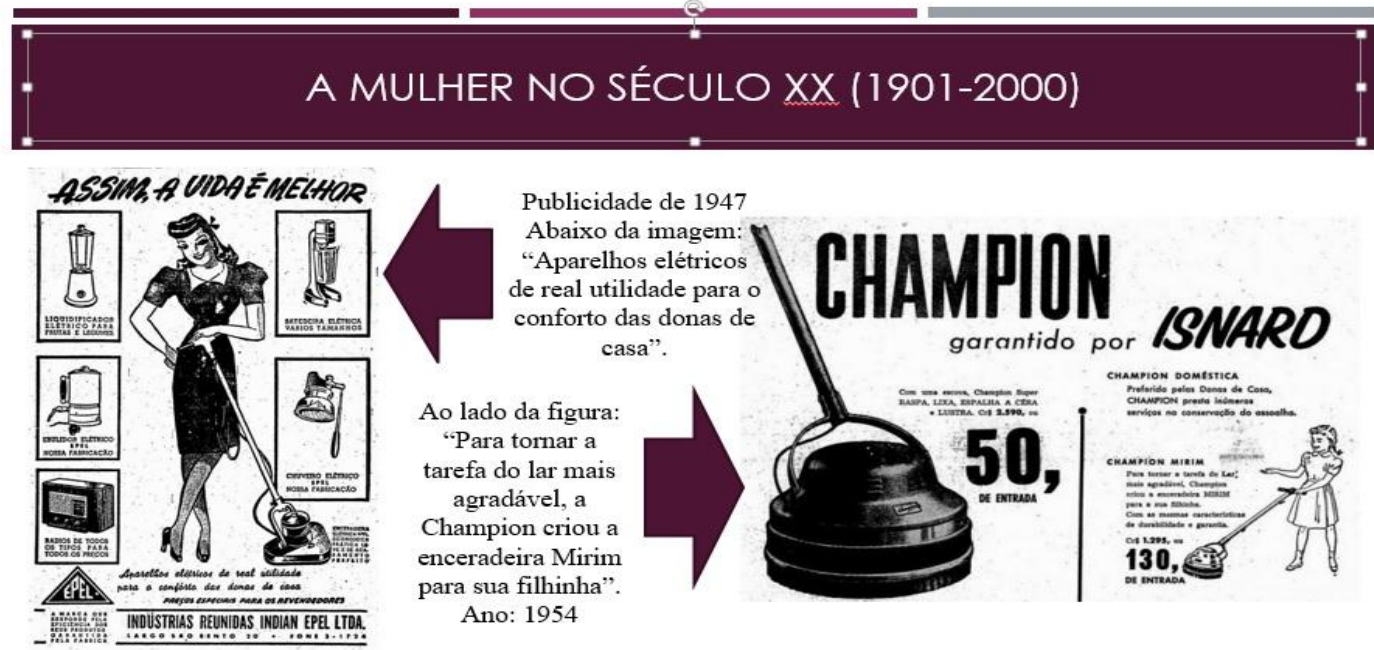

Publicidade de 1947

"Abaixo da imagem:

de real utilidade para o

conforto das donas de

Ao lado da figura: "Para tornar a tarefa do lar mais agradável, a

Champion criou a

enceradeira Mirim

para sua filhinha". casa".

Ano: 1954
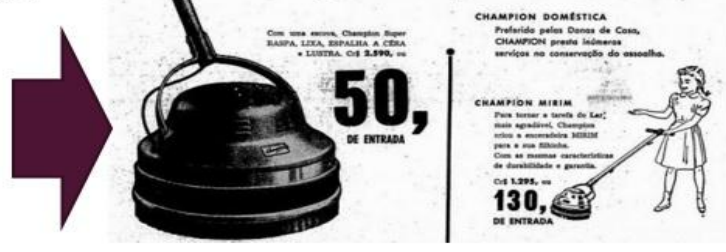

Fonte: Slide elaborado pelos estagiários. ${ }^{3}$

Levamos os alunos a perceberem como a propaganda reforça uma associação entre mulher e lar além de incentivar o mesmo para as meninas. Convém notar como o estudo da história da sociedade com ênfase nas ações das mulheres ainda pode ser considerado como um campo de pesquisa recente, comparado a outras perspectivas. Pois, por um longo período, o conhecimento histórico priorizou os grandes líderes, os governantes, os generais e outros aspectos do espaço público que era - e ainda é - de maioria masculina. A noção de "política" para estes estudos estava muito mais próxima de questões associadas com o Estado e que não valorizavam o ambiente familiar e privado. Dessa maneira, foi também objetivo da oficina oportunizar um debate que desse visibilidade e valorizasse as ações das mulheres no tempo. Isto é, ressaltar que o decorrer da história foi permeado por conflitos e interesses pelo que se "espera" e foi construído das mulheres ou homens.

Depois de apresentarmos uma discussão sobre a história das mulheres, também debatemos a respeito dos movimentos do século XX que buscavam a igualdade entre homens e mulheres e sobre alguns dos desafios atuais para a igualdade dos diferentes gêneros. Para entender o contexto de lutas de mulheres organizadas como um

Imagens disponíveis nos seguintes endereços eletrônicos: Epel (vida melhor para mulheres) - 1947. Propagandas Históricas.com.br. Disponível em: <http://www.propagandashistoricas.com.br/2013/12/epel-vida-melhor-para-mulheres1947.html >. Acesso em: 30 mai. 2016; Enceradeira Infantil Champion - 1954. Propagandas Históricas.com.br. Disponível em: 〈http://www.propagandashistoricas.com.br/2015/01/enceradeira-infantil-champion-1954.html〉. Acesso em: 30 mai. 2016. 
movimento, utilizamos as considerações do texto "Traduzindo o debate: o uso da categoria gênero na pesquisa histórica" de Joana Maria Pedro (2005). Nesse texto, a autora situa as questões de luta da mulher, mulheres, feminismo e gênero e ensina como este se modificou ao longo do tempo, incorporou novas demandas e que essas mudanças foram necessárias para ter uma maior representação diante da diversidade da sociedade. Por exemplo, se em um primeiro momento havia como principal pauta a conquista do voto pelas mulheres, posteriormente, a luta pelo direito ao corpo, com o uso de anticoncepcionais, a discussão do aborto ou igualdade salarial pela mesma função, também tornaram-se reivindicações. Um dos slides que utilizamos para problematizar estas novas demandas e movimentos é a Figura 2.

Figura 2 - Desafios para a igualdade entre homens e mulheres.

\section{DESAFIOS PARA A IGUALDADE ENTRE HOMENS E MULHERES}
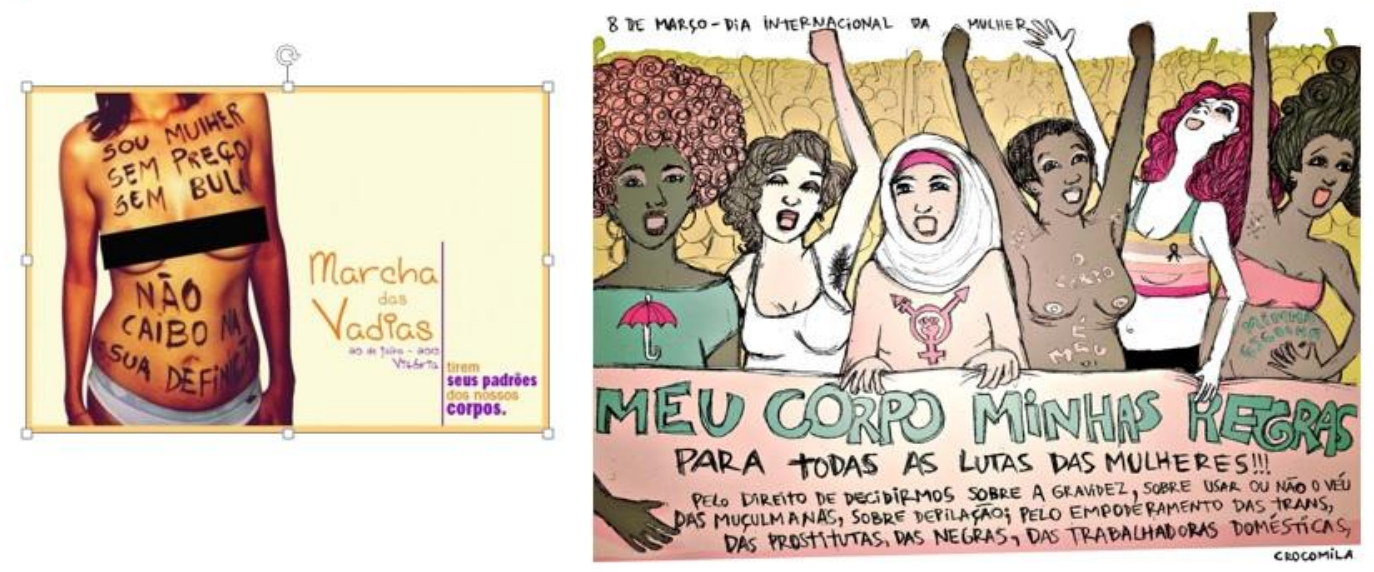

Fonte: Slide elaborado pelos estagiários Andréia e Rodrigo. ${ }^{4}$

Por intermédio das imagens discutimos a complexidade das pautas que movimentos de mulheres demandam atualmente. Convém salientar que a luta das mulheres, conforme já exposto, percebe as diferenças dentro do seu próprio grupo, isto

\footnotetext{
Imagens disponíveis nos seguintes endereços eletrônicos: Marcha das Vadias Rio de Janeiro. Disponível em: $<\mathrm{http} / /$ marchadasvadiasrio.blogspot.com.br/p/cartazes.html >. Acesso em: 30 mai. 2016; Capixabas protestam neste sábado contra a violência sexual na Marcha das Vadias. Folha Vitória. 19/07/2013. Disponível em: <http://www.folhavitoria.com.br/geral/noticia/2013/07/capixabas-protestam-neste-sabado-contra-a-violencia-sexual-namarcha-das-vadias.html>. Acesso em: 30mai. 2016.
} 
é, sabe-se que uma mulher, por exemplo, branca e de classe média enfrenta diferentes desafios que outra, negra e de uma classe social mais baixa. O que não quer dizer que não possa existir uma união em prol de direitos que garantam melhorias para todas as mulheres na sociedade. Nesse sentido, um exemplo abordado na oficina foi a da chamada "Marcha das Vadias", que é um grupo atual de luta pelos direitos das mulheres que existe em diversas cidades. Além disso, pode-se perceber na imagem do cartaz com a frase "meu corpo minhas regras", que parece existir também a intenção de abordar a heterogeneidade racial e religiosa das mulheres envolvidas na luta por igualdade.

Assim, tivemos como objetivo estabelecer um discurso mais próximo da realidade cotidiana de pessoas que não estão sempre a par de discussões acadêmicas. Buscamos mostrar também que a falta de debate ou clareza sobre conceitos envolvidos nesta temática dificulta um melhor entendimento e pode acarretar em preconceitos e críticas infundadas. Um texto que inspirou uma atividade realizada durante a oficina foi "Feminismo para leigos" de Clara Averbuck (2013). A autora discorre sobre como muitas pessoas são contrárias ao feminismo sem sequer saber o que o movimento significa. Muitos tomam partido nesse debate como se o feminismo fosse uma luta contra os homens, e não contra um sistema de dominação que os privilegia.

Feminismo não tem nada a ver com deixar de usar batom, salto ou cercear
sua liberdade sexual [...]. Feminismo não tem nada a ver com esconder o
corpo; muito pelo contrário, exigimos o direito de andar com a roupa que
bem entendermos sem assédio ou constrangimentos [...]. Feminismo tem a
ver com liberdade, com eu, você, elas e eles podermos todos viver e ser sem
ninguém dando pitaco em como devemos nos portar, como devemos nos
vestir, o que devemos dizer, do que devemos fazer com nossos corpos
(AVERBUCK, 2013, s./p.).

Ao final do texto de Clara Averbuck estão presentes uma série de perguntas criadas por Cynthia Semíramis - que visam questionar se a pessoa se identifica com o feminismo:

1. Você concorda que uma mulher deve receber o mesmo valor que um homem para realizar o mesmo trabalho?

2. Você concorda que mulheres devem ter direito a votarem e serem votadas? 3. Você concorda que mulheres devem ser as únicas responsáveis pela escolha da profissão, e que essa decisão não pode ser imposta pelo Estado, pela escola nem pela família?

4. Você concorda que mulheres devem receber a mesma educação escolar que os homens?

5. Você concorda que cuidar das crianças seja uma obrigação de ambos os pais? 
6. Você concorda que mulheres devem ter autonomia para gerir seu dinheiro e seus bens?

7. Você concorda que mulheres devem escolher se, e quando, se tornarão mães?

8. Você concorda que uma mulher não pode sofrer violência física ou psicológica por se recusar a fazer sexo ou a obedecer ao pai ou marido?

9. Você concorda que atividades domésticas são de responsabilidade dos moradores da casa, sejam eles homens ou mulheres?

10. Você concorda que mulheres não podem ser espancadas ou mortas por não quererem continuar em um relacionamento afetivo? (AVERBUCK, 2013, s./p.).

Entregamos aos alunos uma folha com tais perguntas para que respondessem por escrito e, posteriormente, compartilhassem as respostas. No decorrer da atividade os estudantes mostraram-se receptivos para conversar a respeito. Por meio das perguntas foi possível que eles e elas expressassem melhor o que achavam que era feminismo ou gênero. Ou seja, a atividade foi importante para promover uma maior interação e ter mais claro quais eram os saberes prévios da turma.

\section{Algumas palavras finais}

No decorrer deste texto propusemos situar nossa oficina em um contexto maior de discussões sobre gênero, história das mulheres e feminismo. Para isso, mobilizamos autores e autoras que abordaram a temática e buscamos evidenciar o perigo que pode ocasionar quando setores da sociedade pretendem silenciar ou deturpar a busca por igualdade que os estudos de gênero propõem. Nesse sentido, apesar da luta pela igualdade de gênero ter sido constante durante o século XX e início do século XXI, infelizmente, ainda existe o "predomínio de atitudes e convenções sociais discriminatórias em todas as sociedades" (BRASIL, 2009).

Além disso, outros desafios para uma educação que abarque o assunto tratado foram elencados, tais como o receio de tratar de assuntos que podem estar próximos desses estudantes de maneira que possa de alguma forma ofender ou encontrar "cicatrizes" de suas experiências. Embora esses desafios tenham permeado a elaboração e execução da oficina, foi uma experiência rica para nossa formação pessoal e profissional e também diante de manifestações inesperadas por parte de estudantes que se reportaram a aspectos de suas vidas pessoais, relacionados ao que tínhamos como objetivo debater, os de violência doméstica. Convém notar que apesar de termos 
iniciado o processo de elaboração da oficina imaginando reações desde pouco receptivas até mais comunicativas, o que prevaleceu foi a segunda reação.

Ressaltamos, ainda, como foi importante sempre buscarmos tornar mais próximo do cotidiano as discussões da oficina e também sobre como o uso de imagens e vídeos propiciaram uma melhor interação entre nós e os educandos. Sabemos que todo o processo de elaboração e estudo sobre o Núcleo da EJA em que atuamos e o assunto são fundamentais para estarmos melhor preparados no momento da aula. No entanto, como foi uma nova experiência estar na posição de professores, um dos maiores desafios encontrados foi o medo de errar, de esquecer o assunto, de não conseguir envolver os estudantes, dentre outros medos com os quais nos deparamos no exercício da docência. Conjecturamos que com o passar dos tempos, na prática diária, esses receios serão ultrapassados e essa experiência de ensino no estágio para sempre será lembrada e ressignificada. Foi uma etapa muito significativa de nossa formação para atuarmos como futuros professores e professoras de História.

\section{Referências}

AGÊNCIA Brasil. Estudo mostra que 1,3 milhão de jovens de 15 a 17 anos abandonam a escola. 27/02/2016. Disponível em: <http://agenciabrasilebc.com.br/educacao/noticia/2016-02/13-milhao-dejovens-entre-15-e-17-anos-abandonam-escola-diz-estudo>. Acesso em: 15 fev. 2017.

AVERBUCK, Clara. Feminismo para leigos. Carta Capital. 28/06/2013. Disponível em: <http://www.cartacapital.com.br/blogs/feminismo-pra-que/feminismo-para-leigos3523.html>. Acesso em: 30 mai. 2016.

BIROLI, Flávia. A 'ideologia de gênero' e as ameaças à democracia. Blog da Boitempo. Disponível em: <https://blogdaboitempo.com.br/2015/06/26/a-ideologia-de-genero-eas-ameacas-a-democracia/>. Acesso em: 15 mai. 2016.

BRASIL. Lei n. 13.005 de 25 de junho de 2014. Aprova o Plano Nacional de Educação-PNE e dá outras providências. Disponível em: <http://www.planalto.gov.br/CCIVIL_03/_Ato20112014/2014/Lei/L13005.htm>. Acesso em: 16 mai.2016.

Gênero e Diversidade na Escola. Formação de Professoras/es em Gênero, Sexualidade, Orientação Sexual e Relações Étnico-Raciais. Livro de Conteúdo. Versão 2009, Rio de Janeiro: CEPESC; Brasília : SPM, 2009.

FOLHA VITÓRIA. Capixabas protestam neste sábado contra a violência sexual na Marcha das Vadias. 19/07/2013. Disponível em: <http://www.folhavitoria.com.br/geral/noticia/2013/07/capixabasprotestam-neste-sabado-contra-a-violencia-sexual-na-marcha-das-vadias.html $>$. Acesso em: 30 mai. 2016. 
CARTILHA igualdade de gênero. LEGH, Universidade Federal de Santa Catarina, 2015. Disponível em: <http://www.legh.cfh.ufsc.br/files/2015/11/Cartilha-G\%C3\%AAnero-LEGH-Atualizado-13-11Online.pdf $>$. Acesso em: 16 mai. 2016.

CASTRO, Alexandre Silva Bortollini de.; et. al. Nota Técnica $n^{\circ} 24 / 2015$ $C G D H / D P E D H U C / S E C A D I / M E C$. Ministério da Educação. Secretaria de Educação Continuada, Alfabetização, Diversidade e Inclusão. Diretoria de Políticas de Educação em Direitos Humanos e Cidadania. Coordenação Geral de Direitos Humanos. Disponível em: <http://www.spm.gov.br/assuntos/conselho/nota-tecnica-no-24-conceitogenero-no-pne-mec.pdf $>$. Acesso em: 16 mai. 2016.

CATEDRAL METROPOLITANA. N.S. AUXILIADORA GOIÁS. O que é Ideologia de Gênero. Disponível em: <http://www.catedralgo.com.br/index.php/midias/noticias/244-o-que-e-ideologia-degenero >. Acesso em: 29 mai. 2016.

CHRISTO NIHIL PRAEPONERE. Associação Americana de Pediatras fulmina ideologia de gênero. 06/05/2016. Disponível em: <https://padrepauloricardo.org/blog/tag/443ideologia-de-genero>. Acesso em: 29 mai. 2016.

CHAUÍ, Marilena. O que é ideologia. São Paulo: Brasiliense, 1981.

MARCHA DAS VADIAS RIO DE JANEIRO. Disponível em: $<$ http://marchadasvadiasrio.blogspot.com.br/p/cartazes.html>. Acesso em: 30 mai. 2016.

MERCADANTE, Aloízio. MEC repudia tentativas de cerceamento dos princípios e fins da educação brasileira. Ministério da Educação (MEC), 04 de maio de 2016. Disponível em: http://portal.mec.gov.br/component/content/index.php?option=com_content\&view=article\&id=35841\% 3Anota-publica-sobre-tentativas-de-cerceamento-dos-principios-e-fins-da-educacaobrasileira\&catid=211\&Itemid=86>. Acesso em: 15 mai. 2016.

OBSERVATÓRIO INTERAMERICANO DE BIOPOLÍTICA. Você já ouviu falar sobre a "ideologia de gênero"? Disponível em: <http://biopolitica.com.br/index.php/cursos/40-voce-ja-ouviufalar-sobre-a-ideologia-de-genero>. Acesso em: 29 mai. 2016.

PEDRO, Joana Maria. Traduzindo o debate: o uso da categoria gênero na pesquisa histórica. História, São Paulo, v.24, n.1, p.77-98, 2005.

PROPAGANDAS HISTÓRICAS.COM.BR. Enceradeira Infantil Champion - 1954. Disponível em: <http://www.propagandashistoricas.com.br/2015/01/enceradeirainfantil-champion-1954.html>. Acesso em: 30 mai. 2016.

PROPAGANDAS HISTÓRICAS.COM.BR._Epel (vida melhor para mulheres) - 1947. Disponível em: <http://www.propagandashistoricas.com.br/2013/12/epel-vida-melhorpara-mulheres-1947.html>. Acesso em 30 de maio de 2016.

SCOTT, Joan. Gênero: uma categoria útil para análise histórica. Tradução: Christine Rufino Dabal; Maria Betânia Ávila. Disponível em: <http://disciplinas.stoa.usp.br/pluginfile.php/185058/mod_resource/content $/ 2 / G \% C 3 \%$ AAnero-Joan\%20Scott.pdf>. Acesso em: 10 abr. 2016. 
78 Polyphonía, v. 29/1, jan./jun. 2018

TIBURI, Márcia. Como conversar com um fascista: reflexões sobre o cotidiano autoritário brasileiro. Rio de Janeiro: Record, 2015.

WILLYS, Jean. Prefácio. In. TIBURI, Márcia. Como conversar com um fascista: reflexões sobre o cotidiano autoritário brasileiro. Rio de Janeiro: Record, 2015. p.17-22.

Recebido em: 27 abr. 2018.

Aceito em: 28 maio 2018. 